\title{
Maxillary Prominence
}

National Cancer Institute

\section{Source}

National Cancer Institute. Maxillary Prominence. NCI Thesaurus. Code C34206.

An embryonic structure developing from the upper part of the first pharyngeal arch, which gives rise to the upper jaw and palatal shelves. 